\title{
A commentary review on the use of normalized difference vegetation index (NDVI) in the era of popular remote sensing
}

\author{
Sha Huang ${ }^{1,5} \cdot$ Lina Tang $^{2} \cdot$ Joseph P. Hupy ${ }^{3}$. \\ Yang Wang ${ }^{4} \cdot$ Guofan Shao $^{5}$
}

Received: 22 January 2020 / Accepted: 15 May 2020 / Published online: 31 May 2020

(C) The Author(s) 2020, corrected publication 2020

\begin{abstract}
The Normalized Difference Vegetation Index (NDVI), one of the earliest remote sensing analytical products used to simplify the complexities of multi-spectral imagery, is now the most popular index used for vegetation assessment. This popularity and widespread use relate to how an NDVI can be calculated with any multispectral sensor with a visible and a near-IR band. Increasingly low costs and weights of multispectral sensors mean they can be mounted on satellite, aerial, and increasingly-Unmanned Aerial Systems (UAS). While studies have found that the NDVI is effective for expressing vegetation status and
\end{abstract}

Project funding: This study is supported by the USDA National Institute of Food and Agriculture McIntire Stennis project (IND011523MS).

The online version is available at http://www.springerlink.com.

Corresponding editor: YU Lei.

Sha Huang

shuang1126@shnu.edu.cn

Guofan Shao

shao@purdue.edu

1 School of Environmental and Geographical Sciences, Shanghai Normal University, Shanghai 200234,

People's Republic of China

2 Key Laboratory of Urban Environment and Health, Institute of Urban Environment, Chinese Academy of Sciences, Xiamen 361021, People's Republic of China

3 Department of Aviation and Transportation Technology, Purdue University, West Lafayette, IN 47907, USA

4 Zhejiang GeeSpace Technology Co., Ltd, Purdue University, 1535 Hongmei Road, Xuhui District, Shanghai 200030, People's Republic of China

5 Department of Forestry and Natural Resources, Purdue University, West Lafayette, IN 47907, USA quantified vegetation attributes, its widespread use and popularity, especially in UAS applications, carry inherent risks of misuse with end users who received little to no remote sensing education. This article summarizes the progress of NDVI acquisition, highlights the areas of NDVI application, and addresses the critical problems and considerations in using NDVI. Detailed discussion mainly covers three aspects: atmospheric effect, saturation phenomenon, and sensor factors. The use of NDVI can be highly effective as long as its limitations and capabilities are understood. This consideration is particularly important to the UAS user community.

Keywords NDVI - Atmospheric effect - Saturation phenomenon · Calibration · Multispectral · Near infrared · UAS $\cdot$ Drone remote sensing

\section{Introduction}

Multi-spectral remotely sensed imagery contains a combination of bands that creates a composite image to be used for interpretation and analysis. With multi-spectral imagery, the individual bands in the band composite can be transformed to get certain features and patterns to stand out better. Image band transformations have become a common practice to generate new images from two or more image bands for information extraction. The new images generated this way enhance representations to ground objects such as vegetation. There are more than one hundred vegetation indices that have been derived from multispectral imagery (Xue and Su 2017).

Kriegler et al. (1969) proposed a simple band transformation: near-infrared (NIR) radiation minus red radiation divided by near-infrared radiation plus red radiation, 
resulting in a newly simplified image called the Normalized Difference Vegetation Index (NDVI). Like all indices created to simplify what are otherwise complex amalgamations of data, the NDVI is appealing because of its ability to quickly delineate vegetation and vegetative stress, which has great appeal in commercial agriculture and land-use studies. The appeal was quickly recognized by those in the scientific community in the early 1970s, all the earth observation satellite remote sensing data were equipped to produce this index at different spatial and temporal resolutions. For example, at the planetary scale, the generation of global NDVI data sets was given the highest priority by the Pathfinder AVHRR Land Science Working Group (James and Kalluri 1994). For reasons related to its long history, simplicity, and reliance on easily obtainable multi-spectral bands, the NDVI has become the most popular index used for vegetation assessment.

The number of NDVI papers from the Web of Science Core Collection sharply increased from 795 in the 1990s, to 3361 in the 2000s, and to 12,618 in the 2010s. Among the total publications, at least one third of them were associated with forests. The forest-NDVI data sources and application areas experienced notable changes over time (Table 1). For example, AVHRR was replaced with Landsat and MODIS in dominant sensors, and physiology was replaced with phenology in research; climate change and classification became more popular; leaf area index (LAI) became more popular in absolute number but less popular in number percentage. It is worth noting that 'time-series' was among the top three keywords searched for in the 2010s because of continuous availability of NDVI products from AVHRR and MODIS in the past four decades. Pettorelli et al. (2005) suggest NDVI time-series should be smoothed before being used because of noise present in the downloadable NDVI data sets.

The overall purpose of using NDVI is to improve the analysis of information about vegetation with remotely sensed data. Studies have demonstrated that NDVI is effective to differentiate savannah, dense forest, non-forest and agricultural fields and to determine evergreen forest versus seasonal forest types (Pettorelli et al. 2005), and to estimate various vegetation properties, including the LAI (e.g., Tian et al. 2017), biomass (e.g., Zhu and Liu 2015), chlorophyll concentration in leaves (e.g., Pastor-Guzman et al. 2015), plant productivity (e.g., Vicente-Serrano et al. 2016), fractional vegetation cover (e.g., Dutrieux et al. 2015), and plant stress (e.g., Chavez et al. 2016). Such estimations are often derived by correlating remotely sensed NDVI values with ground-measured values of these variables. The reliability of NDVI directly determines the robustness of NDVI-related models (Butt 2018).

Remote sensing data from different platforms has become increasingly available for end users on the application side of remote sensing. In addition to the increasingly common free
Table 1 Intersections and trends of top 20 keywords identified from forest-relevant DNVI publications within the Web of Science Core Collection in the 1990s, 2000s, and 2010s

\begin{tabular}{|c|c|c|c|}
\hline \multirow[t]{2}{*}{ Keyword } & \multicolumn{3}{|c|}{ The frequency of keyword } \\
\hline & $1990 \mathrm{~s}$ & $2000 \mathrm{~s}$ & $2010 \mathrm{~s}$ \\
\hline AVHRR Data & 24 & 112 & - \\
\hline Biomass & 12 & 43 & - \\
\hline Calibration & 8 & - & - \\
\hline Canopy & 12 & - & - \\
\hline Classification & 13 & 88 & 396 \\
\hline Climate & 17 & 78 & 307 \\
\hline Climate Change & - & 55 & 505 \\
\hline Cover & 10 & 52 & 269 \\
\hline Data Set & 12 & - & - \\
\hline Drought & - & - & 196 \\
\hline Dynamics & 8 & - & 291 \\
\hline Evapotranspiration & 11 & - & - \\
\hline Fire & - & 35 & - \\
\hline Growth & - & 35 & - \\
\hline High-Resolution Radiometer & 14 & - & - \\
\hline Images & 24 & 116 & 315 \\
\hline Landsat & - & 37 & 292 \\
\hline Leaf Area Index & 30 & 129 & 314 \\
\hline Model & 18 & 89 & 219 \\
\hline Modis & - & 114 & 612 \\
\hline Net Primary Production & 11 & 51 & - \\
\hline Patterns & - & 56 & 184 \\
\hline Phenology & - & 60 & 351 \\
\hline Photosynthesis & 20 & - & - \\
\hline Precipitation & - & - & 186 \\
\hline Radiation & 10 & - & - \\
\hline Rainfall & - & 36 & - \\
\hline Random Forest & - & - & 230 \\
\hline Reflectance & 29 & 101 & 187 \\
\hline Spectral Reflectance & 10 & - & - \\
\hline Temperature & - & 48 & 222 \\
\hline Time Series & - & - & 455 \\
\hline Transpiration & 13 & - & - \\
\hline Trends & - & - & 167 \\
\hline Variability & - & 61 & 259 \\
\hline
\end{tabular}

satellite data sources, including MODIS, Landsat, Sentinel, and Gaofen, commercial satellite imagery resolutions continue to increase spatially (e.g., WorldView-3,-4) and temporally (e.g., Planet), thanks to the cost reductions for small satellite systems (Shao 2015). Many forms of commercial satellite imagery available today gather imagery with resolutions not limited so much by technology, but by legal constraints that limits the spatial resolutions or ground sample distances (GSD) that are mainly attributed to national security concerns. Perhaps the most astonishing development 
in remote sensing technology today is the widespread use of unmanned aerial system/ vehicle (UAS/UAV) or simply drone remote sensing (Tang and Shao 2015; Yao et al. 2019). NDVI data have become a commonplace output stemming from UAS industry, and their spatial resolution continues to reach GSD levels that were unimaginable before. As many as 337 NDVI papers associated with UAS/drone/UAV were found from the Web of Science Core Collection in the 2010s, increasing from only three publications in the 2000s.

The rapid advancements in UAS are making the use of NDVI more popular over time. However, many UAS-based NDVI products have shown unprofessional deficiencies, adding new considerations on the use of NDVI. The problems in UAS-based NDVI are the results of the inherent nature of NDVI and lagged education of UAS users. As NDVI continues to dominate the applications of vegetation indices derived from the existing and new remote sensing data sources, NDVI products will be increasingly diversified. The consistent use of NDVI among different sensors and platforms is the key for promoting the effectiveness of NDVI on vegetation assessment across space and over time (Grant 2017). The major problems in NDVI include its atmospheric effect, its ease for saturation, and sensor quality. Here we aim to review and explain these major problems so that NDVI users, particularly the end users lacking in-depth remote sensing knowledge, will take cautious practice with NDVI data.

\section{NDVI calculation}

Mathematically, NDVI is expressed as follows:

$N_{\text {DVI }}=\frac{N_{\text {IR }} \mathrm{NIR}-R_{\mathrm{ed}} \mathrm{Red}}{N_{\mathrm{IR}} \mathrm{NIR}+R_{\mathrm{ed}} \operatorname{Red}}$

where $N_{\mathrm{DVI}}$ is normalized difference vegetation index. $R_{\text {ed }}$ and $N_{\mathrm{IR}}$ are spectral radiance (or reflectance) measurements recorded with sensors in red (visible) and NIR regions, respectively.

Radiance (watts steradian ${ }^{-1} \mathrm{~m}^{-2} \mu \mathrm{m}^{-1}$ ) is the measure of energy flux recorded by a sensor. The values of radiance are often rescaled to digital numbers (DN) as 6-bit or 7-bit (MSS), 8-bit (TM, ETM+), or 12-bit (Landsat8) unsigned integers. Reflectance is a unitless measure of the ratio of radiation reflected by an object relative to the radiation incident upon the object. NDVI values range from -1 to 1 regardless using radiance, reflectance, or DN as input. In general, its values are negative for water bodies, close to zero for rocks, sands, or concrete surfaces, and positive for vegetation, including crops, shrubs, grasses, and forests (Jones and Vaughan. 2010). In other words, greater NDVI values mean stronger implications for vigorous vegetation greenness. The use of reflectance is helpful to reduce the effect of scattered radiation in the atmosphere (Jones and Vaughan. 2010). On clear days, the amount of solar radiation scatter is inversely proportional to the fourth power of the wavelength $\left(\sim \lambda^{-4}\right.$, where, $\lambda$ is wavelength) (Fig. 1). This theory of strong wavelength dependence on atmospheric scattering is known as Rayleigh scattering, and it means that shorter (red) wavelengths scatter stronger as compared to the longer (near infrared) wavelengths, affecting the calculation of NDVI.

The differences in NDVI values among different objects are due to their relative differences in spectral responses (Fig. 1). Thus, Eq. 1 can be changed as follows:

$N_{\text {DVI }}=\frac{R-1}{R+1}$

where $N_{\mathrm{DVI}}$ is normalized difference vegetation index. $R$ is the ratio of NIR to Red, and is commonly referred as to ratio vegetation index (Jones and Vaughan 2010).

Equation 2 is more explicit for explaining NDVI behavior patterns due to different responses of NIR and Red to atmosphere (in the selection below) and stress (McVeagh et al. 2012).

\section{Atmospheric effect}

By referring to Eq. 2 , if $R=2, N_{\mathrm{DVI}}=0.33$; to obtain a NDVI value of $0.80, R$ needs to be equal to 9 . Spaceborne and airborne sensors mix atmosphere-scattered and surfacereflected radiations into data recordings. Due to Rayleigh scattering, radiance in the red region is much greater than that in NIR region. The mid-wavelength values of band 4

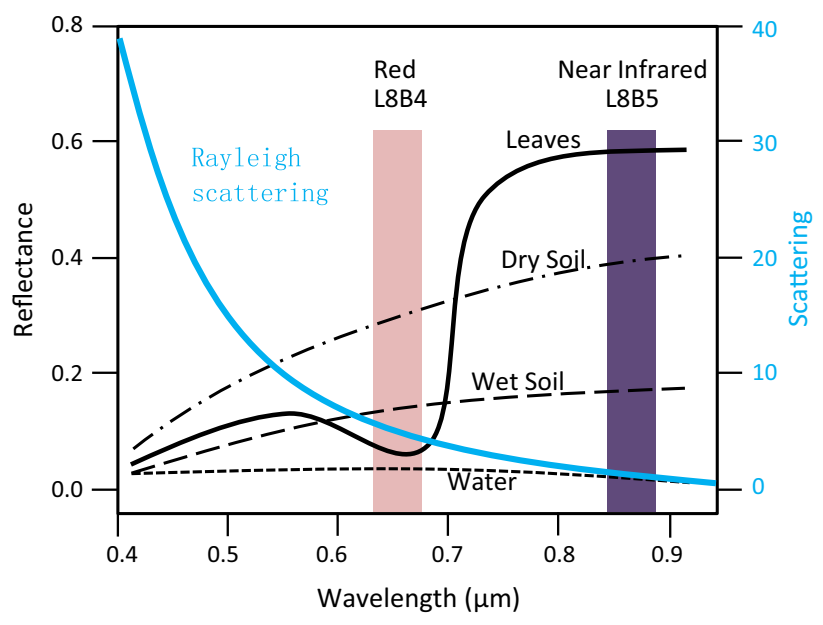

Fig. 1 An illustration of spectral response curves and their intersections with red (Landsat 8 Band 4) and near infrared bands (Landsat 8 Band 5) as well as the wavelength-dependent scattering 
and 5 from Landsat 8 are $655 \mathrm{~nm}$ and $865 \mathrm{~nm}$, respectively. Thus, scattering in the red region is three times higher than in the NIR region. In other words, recorded radiance in the red region contains a much greater proportion of scattering than that in NIR region. In addition, solar radiation in the red region is much greater than that in the NIR region on top of the atmosphere (TOA), elevating scattered-radiation proportions in red radiance recordings more than NIR radiance recorded values. Therefore, NDVI values calculated with TOA radiance (or DN) are generally lower than those calculated with surface reflectance (Fig. 2). The analysis ready data (ARD) provide by Landsat and Sentinel-2 have corrected atmospheric effects and can be used directly to calculate NDVI (Frantz 2019). Because a UAS sensor is frequently so close to ground objects, the atmospheric effect is minimal (e.g., Guo et al. 2019).

\section{Saturation phenomenon}

One commonly recognized problem attributed to NDVI is its insensitivity to changes in environment and/or biomass when environmental conditions and biomass reach to a certain high level. For example, Nicholson and Farrar (1994) noted that the response of NDVI to rainfall was nearly linear at low values of rainfall, but showed little further increase with rainfall at relatively high rainfall values $(50-100 \mathrm{~mm} /$ month) in Botswana; Van Der Meer et al. (2001) found that NDVI values become saturated at larger biomass values ( $>100$ tons/ha) for broadleaved forests. On the other hand, the calculation of NDVI is sensitive to atmosphere, soil, and pixel components. The spectral response to these factors is not exactly the same in the two spectral bands used for NDVI calculation, complicating NDVI behavior patterns. As a result, there are close similarities in NDVI values between a mature deciduous forest and golf course grass (Fig. 2).

\section{Sensor factors}

Sensor types are characterized by varying sensor technologies and platforms, which differentiate remote sensing data sets. Continuous efforts have been made in comparing NDVI values acquired with different sensors. Due to differences in band widths, spatial resolutions, and data processing, different sensors can deliver notably different NDVI behaviors, particularly between spaceborne and airborne sensors (Fig. 2). Van Leeuwen et al. (2006) pointed out that MODIS and VIIRS NDVI data are minimally affected by atmospheric water vapor, while AVHRR NDVI data were substantially reduced by water vapor, making inter-sensor comparison for NDVI calculation even more difficult. Franke et al. (2006) used a hyperspectral dataset to compare NDVI differences directly attributed to band spectral characteristics and found substantial NDVI differences among Landsat
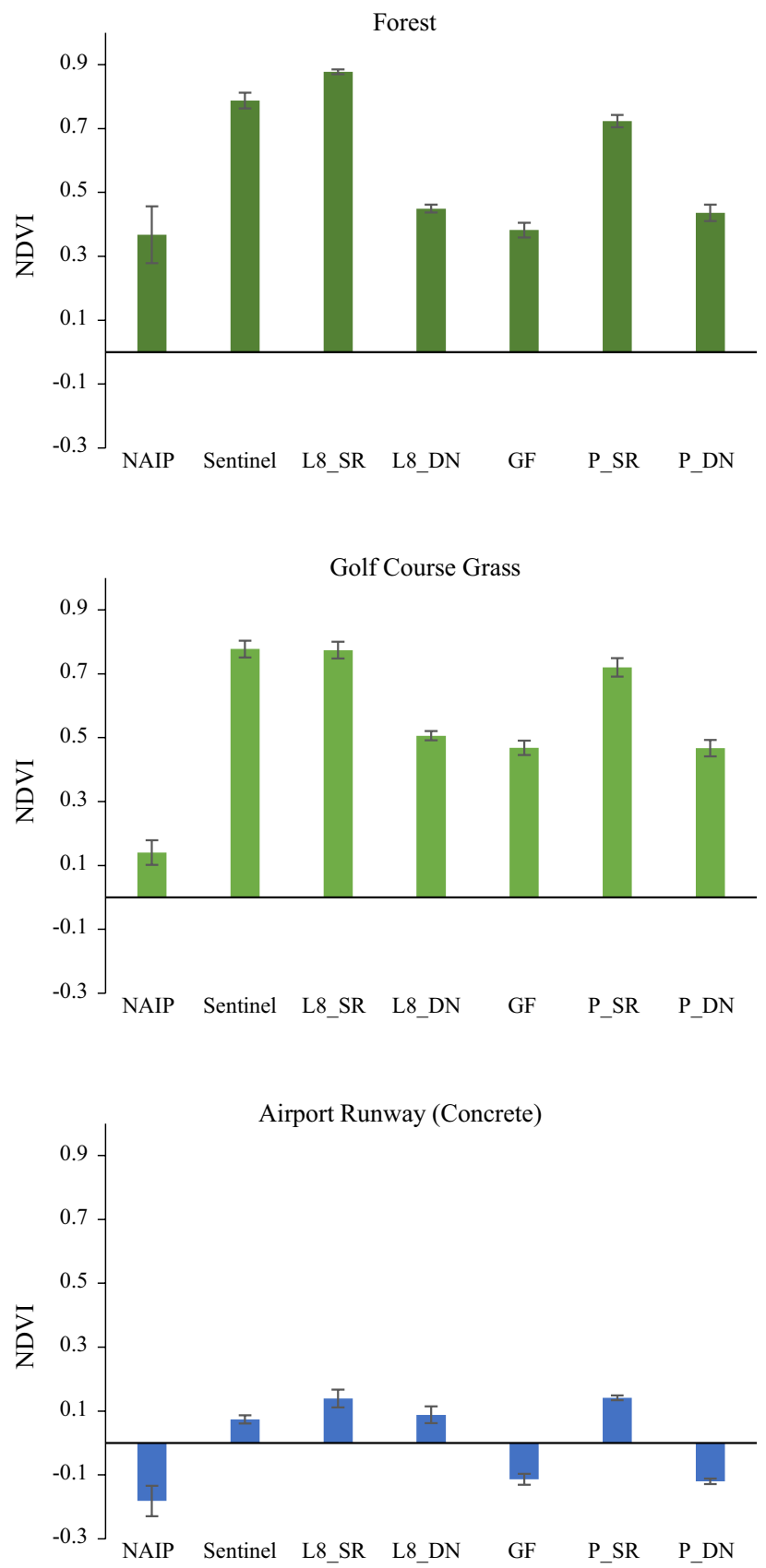

Fig. 2 A comparison of NDVI values for three land cover types and from one aerial and four free satellite data sources acquired in autumn between 2016 and 2019. NAIP is USDA National Agriculture Imagery Program aerial photography ( $0.6 \mathrm{~m}$ pixel size), Sentinel is level-2 surface reflectance data $(10 \mathrm{~m}), \mathrm{L} 8$ _SR is Landsat 8 surface reflectance data $(30 \mathrm{~m}), \mathrm{L} 8$ _DN is Landsat 8 digital number data (30 m), GF is Gaofen-2 data (3 m), P_SR is Planet surface reflectance data $(3 \mathrm{~m})$, and P_DN is Planet digital number data $(3 \mathrm{~m})$. The sampling sites are located in West Lafayette, Indiana, US

5TM, QuickBird and SPOT5. Rossi et al. (2019) found that NDVI inconsistencies among Spectral Reflectance Sensors (SRS), Phenocams, and Sentinel-2 MSI depended on sensor-specific spatial and spectral resolutions and acquisition 
geometries, as well as on vegetation management activities and vegetation growth during the year. Khaliq et al. (2019) demonstrated that $5-\mathrm{cm}$ resolution UAS NDVI was more accurate than 10-m Sentinel-2 NDVI for measuring vineyard variability. Berra et al. (2019) compared UAS and Landsat derived NDVI datasets for tracking forest canopy phenology and found UAS NDVI time series was more effective.

Although UAS sensors maintain high-resolution advantages, the quality of UAS sensors varies greatly (Grant 2017). Unlike high-end satellite systems, which have been thoroughly calibrated, many purported commercial UAS multi-spectral NDVI capable sensors may involve substantial geometric and radiometric errors that need to be reduced through calibration. However, UAS calibration is not a straightforward process (Poncet et al. 2019). Deng et al. (2018) suggest that extra efforts are needed to calibrate UAS sensors and improve UAS data postprocessing for the robust use of UAS NDVI datasets. Mamaghani and Salvaggio (2019) proposed a general technique for characterizing and calibrating spectral sensors for UAS. Particular efforts are needed to calibrate multi-lens systems, which have single or multiple camera bodies, to reduce co-registration errors (Jhan et al. 2018; Wierzbicki 2018) and radiometric errors (Guo et al. 2019; Wierzbicki et al. 2018). Such calibrations are important to UAS-based NDVI because of two reasons. First, NDVI calculation depends on the ratio of the NIR band to the Red band (Eg. 2), and systematic calibrations can improve the ratio value. Second, UAS imagery has high spatial resolutions. In this case, a small error in the viewing angle of a single lens can cause unacceptable geometric distortions between the NIR and Red bands.

\section{Concluding remarks}

The use of NDVI facilitates remote sensing applications in part because it correlates with the status of a broad array of vegetation properties, thus simplifying the complex. At the same time, popular development of remote sensing technology has subsequently promoted the generation of lowcost image data helpful for broadening NDVI applications. Remote sensing has changed the way the land resources are viewed, used, and managed. The same applies toward how NDVI is implicated with vegetation heath, patterns, and status. There is no doubt that NDVI will continue to be a dominate vegetation index, but the effective use of NDVI depends on the quality of multispectral data and the interpretation of NDVI values.

There are no two remote sensing images that are the same. So too with NDVI products. Unlike land-use classifications that can be assessed with reference data, a specific NDVI value does not have a sole interpretation. In this regard, no black/white reference data are available to validate NDVI data utilizing conventional accuracy assessment methods (Shao et al. 2019). For local-scale vegetation management purposes, NDVI is commonly used as a direct indicator of vegetation health and growth (Coops and Stone 2005; McVeagh et al. 2012); for large-scale vegetation monitoring purposes, NDVI is often used as a dependent variable to predict other vegetation attributes that cannot be detected directly with remote sensing imagery. In either case, it is possible to validate the visual or quantitative predictions (Box et al. 1989; Loranty et al. 2018). This validation is necessary to indirectly evaluate the effectiveness of NDVI data used.

Although NDVI has no explicit meanings, and its intent as an index is to simplify the complex, its behaviors can be explained by sophisticated science and technology. NDVI is generally useful if it is obtained with reliable sensors and data processing methods. Although we cannot expect that every user of NDVI products is a remote sensing expert, or that every remote sensing analyst is familiar with sensor calibrations, the unchecked use of NDVI can and should be minimized. Data analysts and data providers should educate NDVI users as much as possible. In the field of UAS, most end users of UAS NDVI data have little knowledge about NDVI, and simply have faith in the appealing pseudo-color of the NDVI images processed and provided by UAS companies. Sometimes the UAS user community is misinformed about the NDVI as a sensor in itself and not as an index. This represents an unnecessary and inconsiderate practice from the UAS industry.

There are a variety of vegetation indices and each has its strength and limitations (Loranty et al. 2018; Xue and Su 2017). NDVI is the most popular index used for vegetation assessment but this does not mean it is universally effective. In case NDVI cannot meet the needs of vegetation assessment or other purposes, one may consider to use other vegetation indices. It is worth noting that every vegetation index has atmospheric and sensor effects, and thus it also has high variability and low repeatability or comparability.

Open Access This article is licensed under a Creative Commons Attribution 4.0 International License (https://creativecommons.org/ licenses/by/4.0/), which permits use, sharing, adaptation, distribution and reproduction in any medium or format, as long as you give appropriate credit to the original author(s) and the source, provide a link to the Creative Commons licence, and indicate if changes were made. The images or other third party material in this article are included in the article's Creative Commons licence, unless indicated otherwise in a credit line to the material. If material is not included in the article's Creative Commons licence and your intended use is not permitted by statutory regulation or exceeds the permitted use, you will need to obtain permission directly from the copyright holder. To view a copy of this licence, visit http://creativecommons.org/licenses/by/4.0/. 


\section{References}

Berra EF, Gaulton R, Barr S (2019) Assessing spring phenology of a temperate woodland: A multiscale comparison of ground, unmanned aerial vehicle and Landsat satellite observations. Remote Sens Environ 223:229-242

Box EO, Holben BN, Kalb V (1989) Accuracy of the AVHRR vegetation index as a predictor of biomass, primary productivity and net $\mathrm{CO}_{2}$ flux. Vegetatio 80:71-89

Butt B (2018) Environmental indicators and governance. Curr Opin Env Sust 32:84-89

Chavez RO, Clevers JGPW, Decuyper M, De Bruin S, Herold M (2016) 50 years of water extraction in the Pampa del Tamarugal basin: Can Prosopis tamarugo trees survive in the hyper-arid Atacama Desert (Northern Chile)? J Arid Environ 124:292-303

Coops NC, Stone CA (2005) A comparison of field-based and modelled reflectance spectra from damaged Pinus radiata foliage. Aust J Bot 53(5):417-429

Deng L, Mao Z, Li X, Hu Z, Duan F, Yan Y (2018) UAV-based multispectral remote sensing for precision agriculture: A comparison between different cameras. ISPRS J Photogramm Remote Sens 146:124-136

Dutrieux LP, Verbesselt J, Kooistra L, Herold M (2015) Monitoring forest cover loss using multiple data streams, a case study of a tropical dry forest in Bolivia. ISPRS J Photogramm Remote Sens 107:112-125

Franke J, Heinzel V, Menz G (2006) Assessment of NDVI-differences caused by sensor specific relative spectral response functions. In: Proceedings of IEEE international conference on geoscience and remote sensing symposium. Denver, CO, pp 1138-1141

Frantz D (2019) FORCE-Landsat+ Sentinel-2 analysis ready data and beyond. Remote Sens 11(9):1124-1145

Grant BG (2017) UAV imagery analysis: Challenges and opportunities. In: Proceedings of the long-range imaging II. Anaheim, CA, vol 10204, p 1020406

Guo Y, Senthilnath J, Wu W, Zhang X, Zeng Z, Huang H (2019) Radiometric calibration for multispectral camera of different imaging conditions mounted on a UAV platform. Sustainability 11(4):978-1001

James ME, Kalluri SNV (1994) The Pathfinder AVHRR land data set: an improved coarse resolution data set for terrestrial monitoring. Int J Remote Sens 15(17):3347-3363

Jhan JP, Rau JY, Haala N (2018) Robust and adaptive band-to-band image transform of UAS miniature multi-lens multispectral camera. ISPRS J Photogramm Remote Sens 137:47-60

Jones HG, Vaughan RA (2010) Remote sensing of vegetation: principles, techniques, and applications. Oxford University Press, New York, p 353

Khaliq A, Comba L, Biglia A, Ricauda Aimonino D, Chiaberge M, Gay P (2019) Comparison of satellite and UAV-based multispectral imagery for vineyard variability assessment. Remote Sens 11(4):436-452

Kriegler FJ, Malila WA, Nalepka RF, Richardson W (1969) Preprocessing transformations and their effect on multispectral recognition. Remote Sens Environ VI:97-132

Loranty M, Davydov S, Kropp H, Alexander H, Mack M, Natali S, Zimov N (2018) Vegetation indices do not capture forest cover variation in Upland Siberian larch forests. Remote Sens 10(11):1686-1700

Mamaghani B, Salvaggio C (2019) Multispectral sensor calibration and characterization for sUAS remote sensing. Sensors 19(20):4453

McVeagh P, Yule I, Grafton M (2012) Pasture yield mapping from your groundspread truck. In: Advanced Nutrient Management:
Gains from the Past - Goals for the Future. (Eds L.D. Currie and C L. Christensen). http://flrc.massey.ac.nz/publications.html. Occasional Re-port No. 25. Fertilizer and Lime Research Centre, Massey University, Palmerston North, New Zealand, pp 24-29

Nicholson SE, Farrar TJ (1994) The influence of soil type on the relationships between NDVI, rainfall, and soil moisture in semiarid Botswana. I. NDVI response to rainfall. Remote Sens Environ 50(2):107-120

Pastor-Guzman J, Atkinson P, Dash J, Rioja-Nieto R (2015) Spatiotemporal variation in mangrove chlorophyll concentration using Landsat 8. Remote Sens 7(11):14530-14558

Pettorelli N, Vik JO, Mysterud A, Gaillard JM, Tucker CJ, Stenseth NC (2005) Using the satellite-derived NDVI to assess ecological responses to environmental change. Trends Ecol Evol 20(9):503-510

Poncet AM, Knappenberger T, Brodbeck C, Fogle M, Shaw JN, Ortiz BV (2019) Multispectral UAS data accuracy for different radiometric calibration methods. Remote Sens 11(16):1917-1938

Rossi M, Niedrist G, Asam S, Tonon G, Tomelleri E, Zebisch M (2019) A comparison of the signal from diverse optical sensors for monitoring alpine grassland dynamics. Remote Sens 11(3):296-317

Shao GF (2015) Optical remote sensing. In: Richardson D (ed) The international encyclopedia of geography: people, the earth, environment, and technology, 2nd edn. Wiley, Chichester, pp 2390-2395

Shao GF, Tang LN, Liao JF (2019) Overselling overall map accuracy misinforms about research reliability. Landsc Ecol 34(11):2487-2492

Tang LN, Shao GF (2015) Drone remote sensing for forestry research and practices: a review. J For Res 26(4):791-797

Tian J, Wang L, Li X, Gong H, Shi C, Zhong R, Liu X (2017) Comparison of UAV and WorldView-2 imagery for mapping leaf area index of mangrove forest. Int J Appl Earth Obs Geoinf 61:22-31

Van Der Meer F, Bakker W, Scholte K, Skidmore A, De Jong S, Clevers JGPW, Addink E, Epema G (2001) Spatial scale variations in vegetation indices and above-ground biomass estimates: implications for MERIS. Int J Remote Sens 22(17):3381-3396

Van Leeuwen WJ, Orr BJ, Marsh SE, Herrmann SM (2006) Multisensor NDVI data continuity: uncertainties and implications for vegetation monitoring applications. Remote Sens Environ 100(1):67-81

Vicente-Serrano SM, Camarero JJ, Olano JM, Martín-Hernández N, Peña-Gallardo M, Tomás-Burguera M, Gazol A, Azorin-Molina C, Bhuyan U, El Kenawy A (2016) Diverse relationships between forest growth and the normalized difference vegetation index at a global scale. Remote Sens Environ 187:14-29

Wierzbicki D (2018) Multi-camera imaging system for UAV photogrammetry. Sensors 18(8):2433-2454

Wierzbicki D, Fryskowska A, Kedzierski M, Wojtkowska M, Delis P (2018) Method of radiometric quality assessment of NIR images acquired with a custom sensor mounted on an unmanned aerial vehicle. J Appl Remote Sens 12(1):015008

Xue J, Su B (2017) Significant remote sensing vegetation indices: a review of developments and applications. J Sensors 2017:1353691

Yao H, Qin R, Chen X (2019) Unmanned aerial vehicle for remote sensing applications—a review. Remote Sens 11(12):1443-1463

Zhu X, Liu D (2015) Improving forest aboveground biomass estimation using seasonal Landsat NDVI time-series. ISPRS J Photogramm Remote Sens 102:222-231

Publisher's Note Springer Nature remains neutral with regard to jurisdictional claims in published maps and institutional affiliations. 